\title{
InTERnATIONAL StUdent PERCEPTION OF COLlaborative GROUP EXAMS IN A FIRST-YEAR ENGINEERING CHEMISTRY COURSE
}

\author{
Roza Vaez Ghaemi ${ }^{1}$, Agnes Peragovics ${ }^{2}$, and Gabriel Potvin ${ }^{1,2}$ \\ ${ }^{1}$ Department of Chemical and Biological Engineering, University of British Columbia \\ ${ }^{2}$ Applied Science Stream, Vantage College Program, University of British Columbia \\ ghaemi@chbe.ubc.ca; gabriel.potvin@ubc.ca
}

\begin{abstract}
Two-stage collaborative exams have previously been shown to improve students' understanding and long-term retention of material, while helping to develop collaborative skills. Very little work has been done, however, on the impact of this practice on international students, who may be faced with particular challenges or contexts.. Building on previous work, the perception of first-year international students in an engineering chemistry course offered as part of the Vantage College Applied Science program at UBC regarding the practice of two-stage exams was assessed before and after participating in one for the first time. Although the experience was overall very positive, and the anticipated difficulties of the midterm seemed to be overestimated, several key challenges must be addressed before deciding whether to continue with this practice as part of this program, namely communication barriers preventing the effective participation of all group members, and a structural competitiveness that may discourage collaboration, both of which are inherent to the Vantage APSC program, as well as frustration associated with mixed technical proficiencies of group members, which is a more typical concern associated with this type of assessment.
\end{abstract}

Keywords: First Year Education, Group Exams, International Students, Collaborative Learning

\section{INTRODUCTION}

Two-stage exams, consisting of a conventional individual exam followed by a collaborative group assessment, have been shown to be effective at enhancing student understanding and long-term retention of the material being tested [1-3], and developing collaborative teamwork and cooperation skills [4-5]. Students are typically more actively engaged with course material during exams than at any other time throughout the term, which makes the opportunity to receive immediate formative feedback from their peers during group exams, allowing them to review and correct misconceptions on the tested material immediately, as opposed to the delayed review that takes place after receiving marks for a conventional exam, all the more valuable. This, again, strengthens their understanding and retention of the material [6]. Other studies have shown that group exams help students to improve their technical communication skills and develop a higher level of understanding and reasoning [7-8]. Although these types of assessments are increasingly popular across different disciplines, reports on the use of collaborative exams in engineering courses, or of student perceptions of this practice, remain scarce.

In previous work we described the implementation of a two-stage midterm in two first year engineering chemistry courses for international students offered as part of the Applied Science (APSC) stream of the Vantage College (VC) program at UBC, and the students' perception of the value of this approach [4]. VC was established to offer innovative specialized first-year programs to international students that are academically very strong but whose language proficiency falls just short of that required for direct entry into UBC's programs. During their first year students in VC follow a special curriculum that integrates regular engineering academic requirements with contextspecific language instruction, based on the Systemic Functional Linguistics (SFL) framework. In the previous study, VC students were asked to complete surveys, administered before and after the implementation of conventional (individual) and two-stage midterms, which were used to assess their perception of the two-stage midterm approach and what benefits or drawbacks they associated with them. This was done in APSC 182 - Matter and Energy I and APSC 183 - Matter and Energy II, first year engineering chemistry courses taken by all VC students, which cover basic inorganic and physical chemistry, equations of state, thermodynamics, material science, solution chemistry, and electrochemistry, and which contain a variety of assessments including takehome assignments (10\% of final mark), team work problems, group lab reports $(20 \%)$, a midterm $(20 \%)$ and a 
final exam $(50 \%)$. The courses are divided into individual self-contained content modules, which although sometimes related, do not explicitly build on each other content-wise. Results from the surveys indicated that students found the group midterm experience to be overall quite positive, and that they generally tended to overestimate the difficulty, stress and potential for conflict during this kind of exam before having actually written one. Results did, however, present some interesting questions that warranted further investigation.

Building on this work and to further characterize some of these identified data trends, a new set of surveys was administered before and after the implementation of a twostage midterm in the same APSC 182 course, to a new cohort of 70 students for which this was the first time participating in collaborative exams. Like in previous years, the cohort was quite diverse, with students coming from over a dozen countries. A significant majority of the cohort (approximately 75\%) came from mainland China, although a lot of internal diversity was observed in the latter group in terms of personal, cultural and academic backgrounds. All students scored in a similar band on language proficiency exams, making them eligible for the $\mathrm{VC}$ program. In the surveys, in addition to questions on their perception of the group midterm practice similar to those asked in the previous study, questions regarding perceived challenges associated with collaborative exams specifically relevant to international students and to the particular context of VC courses were included, notably related to technical communication skills, teamwork, and the value of collaboration in the particular competitive environment in which they study. To further explore or clarify interesting trends in survey results, students were invited, on a purely voluntary basis, to their choice of individual interviews or a general focus group, during which they could share and clarify their thoughts. Responses to the surveys and interviews were subjected to a thematic analysis to identify common and recurring ideas. This paper presents the key results of this process.

\section{METHODOLOGY}

The study seeks to further evaluate international students' perception of the value and experience of writing group exams, and explore how the particular context in which students are working in VC APSC may impact these perceptions. A mixed method approach was selected to achieve this. Quantitative results, in the form of Likertscale survey questions, were collected to assess changes in student perception on key indicators before and after having participated in a group exam, and qualitative responses to open-ended survey questions were analyzed to explain and provide more context for the collected quantitative results and allow respondents to further comment on their experience or provide insight on if and how the VC environment affected it.
A two-stage midterm was administered in APSC $182-$ Matter and Energy I, the first-year engineering chemistry course described above. No student had ever previously participated in a group exam. The students first completed the midterm individually as they would any other exam, and immediately following that, as part of a group of 4 to 5 students, completed a modified exam consisting of identical and very similar questions. Students were randomly assigned to groups, with minor adjustments made by the course instructor to ensure that each group had at least one stronger student, defined as a student from the top third of the course rankings (as assessed from performance in assignments, labs, and exams in all $\mathrm{VC}$ engineering courses to date, which are tracked as standard practice in the program). Although students had not formally worked in these teams before, they were made aware of their team members several days before the exam. Since the course does, by design, contain multiple occasions to work with different team members in laboratory and problem-solving sessions, and that formal instruction on teamwork in diverse teams and its importance not only in the context of engineering studies, but for the engineering profession, is provided, students were prepared for the experience of working in this particular context. During the collaborative portion of the exam, students were encouraged to present and defend their reasoning for their answers to each problem using English, and to try come to an agreement before submitting an answer. The individual portion of the exam counted for $85 \%$ of each student's midterm grade, with the balance attributed to the group stage mark.

To evaluate students' perception of the group exam practice and their assessment of their own learning, a short voluntary survey was administered immediately before (survey open for 4 days before) and immediately after (survey open for 4 days after) the midterm. Given the short time frame and timeliness of data collection, survey responses were attributed to the exam experience and not to other external or developmental factors. Students were encouraged to complete the survey in exchange for a bonus point on their midterm grade if a participation rate of more than $80 \%$ was reached. The survey followed an opt-in format where students were asked whether they consented to their responses being used in aggregate form for this study, with no penalty associated with a refusal. In the survey, students were prompted to assess their own abilities and comfort with the course material, and identify the most significant anticipated (pre-exam) or experienced (post-exam) benefits and challenges associated with the group portion of the exam by indicating their agreement with a list of statements using a 5-point Likert scale $(1=$ strongly disagree; $2=$ disagree; $3=$ neither agree nor disagree; $4=$ agree $; 5=$ strongly agree) and answering two open-ended text-response questions. The full list of questions is shown in Table 1, along with the short-hand tags used in the figures to refer to them in the remainder of 
this paper. Affective questions like "Did you like the 2stage exam experience?" were asked in previous work [4] and not repeated here, but discussions along this line were held during interviews and the focus group. Although the data was anonymous, a unique student-generated 8-digit identifier was used by the participants to allow the comparison of individuals' responses before and after the midterm. Question 5 in Table 1 was included as a quality assurance check, to allow for the screening out of unreliable responses (e.g. those generated by random responding or improper reading of the questions). Likertscale survey responses from students that incorrectly answered this question (by answering anything other than the prescribed response) were deemed unreliable and not included in the analysis. Responses to open-ended questions however, since they do require thinking and can be evaluated for depth or thoughtfulness, were included for all participants, whether or not they correctly answered the Q5, assuming permission to use aggregate data was granted.

Table 1. Survey, questions used in this study. Reference tags included in brackets.

\section{5-Point Likert Scale Questions}

1. I am capable of improving my performance in this course and my understanding of course concepts. (tag: performance)

2. I want to improve my knowledge of course concepts. (tag: improve)

3. I know how to improve my knowledge of course concepts. (tag: how to improve)

4. I am able to do well on tests and other assessments of this course. (tag: do well)

5. I am able to read this statement with care (please choose "Somewhat disagree" as the answer to this question)

6. I am able to make a valuable contribution during the group portion of the midterm. (tag: contribution)

7. I am confident that my English language communication skills are sufficient to effectively work with my team during the group portion of the midterm. (tag: English/communication)

8. I feel that my technical knowledge of the course material is sufficient to allow me to contribute adequately to the group portion of the midterm. (tag: technical knowledge)

Open-ended Text Questions

1. What do you think will be the biggest challenge during the group portion of the exam?

2. What do you think will be the main advantage of the group exam format?

Survey results were analyzed, and trends in responses warranting further investigation were identified (e.g. by significant increases or decreases in scores to particular questions before and after the exam). To gather more information on these trends, all students were sent an invitation to voluntarily participate in their choice of a focus group or one-on-one interviews during which they would provide more detailed information on their experience with, and opinion of, the group exam format, the challenges encountered, along with providing their opinions on possible reasons behind the trends observed. In addition to this general invitation, students with significant differences in their individual and group stage marks, defined as increases of more than $30 \%$ or decreases larger than $10 \%$ on the group portion compared to the marks on the individual component of the exam, were specially invited to a voluntary interview during which they were invited to discuss their experience and shed some light on the reasons behind the grade change. The interviews and focus group were semi-structured, framed around the questions listed in Table 2, but allowing for follow-up questions and discussions to clarify or explore particular responses. All interviews and the focus group were conducted and recorded by the $3^{\text {rd }}$ author of this paper, as an objective party not directly involved with the course in which this study was performed. Each one-onone interview was scheduled for 30 minutes, and the focus group for 45 minutes. Coding for a thematic analysis of the survey open-ended questions and transcripts of recordings of the responses to interview and focus group questions (discussed in greater detail in the following section) was done by the first author of this paper, and results were cross-validated by the other authors prior to analysis.

Table 2. Focus group and interview questions

\begin{tabular}{|l|l|}
\hline $\begin{array}{l}\text { Focus group } \\
\text { framing } \\
\text { questions }\end{array}$ & $\begin{array}{l}\text { 1. How was your experience with the two-stage } \\
\text { midterm? What went well and what did not? } \\
\text { 2. Why do you think communication was perceived } \\
\text { as less of a challenge after trying the two-stage exam? } \\
\text { 3. Why do you think students saw less value in the } \\
\text { two-stage exam in terms of peer helping? }\end{array}$ \\
\hline $\begin{array}{l}\text { Interview } \\
\text { qraming } \\
\text { questions }\end{array}$ & $\begin{array}{l}\text { 1. Your grade improved (or decreased) significantly } \\
\text { during the group exam, can you explained what } \\
\text { happened? } \\
\text { 2. Do you feel you benefitted from the experience, } \\
\text { how so? } \\
\text { 3. Did you enjoy the experience? Would you want to } \\
\text { have group exams in future? }\end{array}$ \\
$\begin{array}{l}\text { 4. Would considering the competition for second year } \\
\text { placement, change your willingness to have more } \\
\text { such kind of exam in future? }\end{array}$ \\
\hline
\end{tabular}

Finally, in an effort to assess the possible impact of the group exam practice on learning and longer-term retention of content, two concepts of similar complexity that were both eligible for assessment on the midterm were tested 
during the final exam. One of the concepts was indeed assessed during the two-stage midterm as a problem to solve, while the other concept was not, but both were covered in some of the practice problems provided to students to help them study. Learning was assessed based on the number of students correctly answering each of these questions on the final exam. A paired two-tailed $t$-test was used to determine statistically significance of student learning with or without collaborative learning. This study received BREB approval at $\mathrm{UBC}$.

\section{RESULTS AND DISCUSSION}

The participation rate for the pre-midterm and postmidterm surveys were $94 \%(n=66)$ and $78 \% \quad(n=55)$, respectively. Of the collected responses, only approximately $40 \%$ both answered the validation question successfully, and gave permission for their responses to be included in the study, allowing for the use of the Likertscale questions in the analysis.

\subsection{Self-Assessment Multiple Choice Questions}

The tabulated responses to the self-assessment Likertscale questions are presented in Figure 1. Although the aggregated average of responses to these multiple choice questions before and after the group exam did not change significantly, an analysis of individual responses (using the student-generated identifying code) yielded interesting results. After the group midterm, $28 \%$ of respondents were more confident, and $21 \%$ were less confident in their technical knowledge, which presents an interesting polarization further addressed during the focus group and interviews. Despite these changes, only two respondents reported changes ( \pm 2 scale points) in their self-confidence regarding their ability to contribute to their group. This may suggest that some students associate being right or wrong or either winning an argument or being overruled during a discussion on the correct answer to a question with the strength of their technical knowledge, but generally remain confident in their ability to make valuable contributions to the team. This is further supported by some of the focus group responses discussed in a subsequent section. The small decrease in the average score of the "do well" question is likely attributable to a slight overconfidence going into an exam, which is not unusual for first-year students in their first term of their studies. The slight uptick in the average score in the "English/communication" question, in conjunction with the analysis of the responses to the open-ended question, suggests that despite the students entering the program with weaker English language skills (a characteristic of VC students), they overestimate the challenge of communicating with team mates, and fared better in that regard than anticipated. Overall the students are confident in their technical skills and their abilities to master the material and learn as needed.

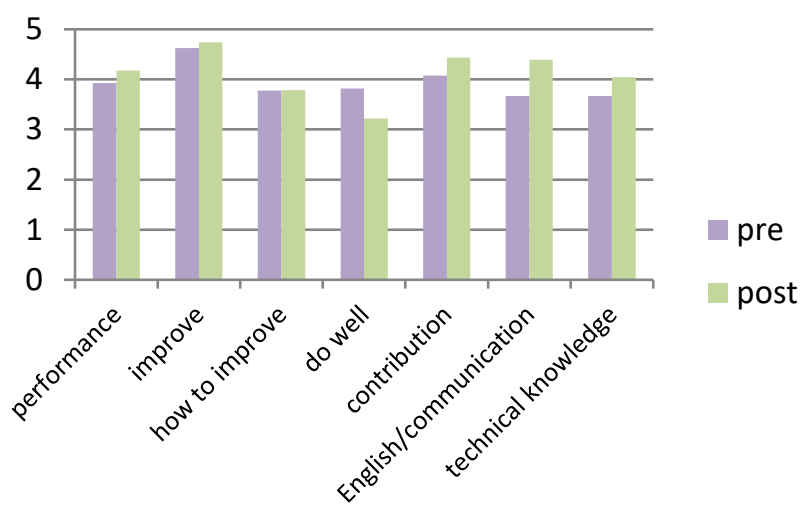

Fig 1. Weighted average of the responses to the selfassessment multiple choice questions on the survey before and after two-stage midterm

\subsection{Open-Ended Questions on the Anticipated and Experienced Challenges and Benefits of Group Exams}

Two open-ended questions were asked to assess what students thought of the group exam format before and after having written one (See Table 2), in order to identify any specific sources of apprehension that could be better addressed in future iterations of the exam, identify benefits that could be strengthened to improve student buy-in for this process, as well as to gain insight into the state of the collaborative environment within the Vantage context, which presents some unique challenges. Responses to these questions were coded and divided into 5 categories for analysis. The categories and codes used are presented in Table 3, and the results are summarized in Figure 2.

Some interesting trends were observed in the responses to these open-ended questions. Before the exam, difficulties with communication among team members were identified in $43 \%$ of responses, and seemed in fact to be the most concerning aspect of the upcoming group midterm. Given the nature of the VC program, this is perhaps unsurprising. In the post-exam survey, communication-related challenges were only identified in $27 \%$ of responses, suggesting that students either overestimated the difficulties of discussing the class material, or underestimated their abilities in technical communication in this context. This is shown in post-exam survey responses like:

\section{"It was pretty easy to discuss the information and technical content of the exam in English."}

"Not a big deal on English communication and discussing technical content in our group; but heard some friends reminding their teammates to speak English." 
Table 3. Coding scheme applied to students' responses to the open-ended survey questions, and tabulated results. Students could have identified multiple challenges or advantages.

\begin{tabular}{|c|c|c|c|c|}
\hline \multicolumn{2}{|c|}{ Code } & Code identifiers (students key words) & $\begin{array}{l}\text { No. of times } \\
\text { mentioned }\end{array}$ & $\begin{array}{l}\text { No. of times } \\
\text { mentioned }\end{array}$ \\
\hline \multirow{5}{*}{ 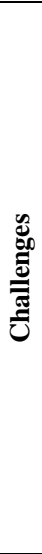 } & Communication & $\begin{array}{l}\text { language, language barrier, (poor) English, understand question, communication, } \\
\text { discussing, understanding each other, conversation, hard to talk not knowing each } \\
\text { other, members not speaking English, start the conversation }\end{array}$ & 29 & 15 \\
\hline & $\begin{array}{l}\text { Consensus and } \\
\text { Agreement }\end{array}$ & $\begin{array}{l}\text { clash of perspectives, disagreement, agreement, deciding the right answer, } \\
\text { divergence, argument, common answer, integrating answers, choose one answer, } \\
\text { debating on correct answer, distribution about answers, hard to judge the right } \\
\text { answer, Everyone thinks they are right, they don't listen!, Keeping their own } \\
\text { opinion, different perspective/result/opinion/characteristics/answer/ideas }\end{array}$ & 20 & 19 \\
\hline & $\begin{array}{l}\text { Contributions and } \\
\text { Teamwork }\end{array}$ & $\begin{array}{l}\text { Cooperation, collaborative work, teamwork, weak partner, uncooperative } \\
\text { members, distribution of the work, different proficiency/responsibility/knowledge } \\
\text { level, not enough contribution, leading the team, non-joining members, } \\
\text { contribution }\end{array}$ & 7 & 5 \\
\hline & Content Knowledge & $\begin{array}{l}\text { hard to answer, question type, contribution without knowledge, calculation, } \\
\text { formula, method of solving the problem, finding variables, having no idea }\end{array}$ & 3 & 3 \\
\hline & Miscellaneous & $\begin{array}{l}\text { test difficulty, time, being nervous to share ideas, being upset, grade improvement } \\
\text { for weaker team members, lower grade, knowing the mistakes, too many } \\
\text { challenges of the new experience, being shy to express oneself, }\end{array}$ & 7 & 13 \\
\hline \multirow{7}{*}{ 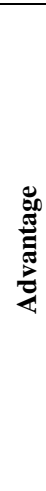 } & Communication & English, communication skills, discussion, expression & 5 & 3 \\
\hline & $\begin{array}{c}\text { Peer } \\
\text { Helping/Teaching }\end{array}$ & $\begin{array}{l}\text { learn from others, improve one's own, understand when others explain, help each } \\
\text { other, enhanced learning, learn faster, learn from mistakes, check each other's } \\
\text { work, re-understand questions, understand immediately, }\end{array}$ & 17 & 15 \\
\hline & Teamwork & $\begin{array}{l}\text { group working skills, contribution, team work, working together, feeling of } \\
\text { participation, combined strengths, how others work }\end{array}$ & 7 & 1 \\
\hline & $\begin{array}{l}\text { Discussion and Idea } \\
\text { Exchange }\end{array}$ & $\begin{array}{l}\text { Discussion, combine ideas/knowledge, different views/ways/perspectives, more } \\
\text { information/ideas, more accurate, all possibilities, share ideas, best solution, work } \\
\text { together, find the right/correct answer, }\end{array}$ & 28 & 27 \\
\hline & Grade Improvement & $\begin{array}{l}\text { better results, improve grades, high chance of getting the right answer, higher } \\
\text { individual mark/grade/score, improved failure rate }\end{array}$ & 3 & 5 \\
\hline & Efficiency & effective, efficient, saves time, faster & 3 & 4 \\
\hline & Miscellaneous & $\begin{array}{l}\text { Easier, copying the answers, interesting, less work and stress/pressure, avoid small } \\
\text { calculation mistakes, find mistakes/weaknesses, I don't know!, make new friends!, } \\
\text { new experience, no advantage, no sense of seriousness/group work, }\end{array}$ & 3 & 4 \\
\hline
\end{tabular}

This is supported by the multiple choice question responses discussed earlier. Since the majority of the exam required the solving of mathematical problems, anticipated difficulties in inter-member communication may have, by virtue of the limited verbal communication requirements, been exaggerated in students' minds before the exam. Some groups also overcame communication issues using their native language, which may further explain this drop, as hinted at in the response above and in comments like:

"We have mostly used English to discuss the answers in our group, however, for some of the words we used Chinese to talk about them",

During the interview process, discussed later, this came out as one of the drawbacks of this practice, with one nonChinese student (Chinese students being the dominant group in the cohort) indicating they felt alienated from their group when they reverted to their native language to quickly overcome communication issues.

A more surprising change, regarding perceived benefits of group exams, is observed in responses related to the value of teamwork. Before the exam the opportunity to work as a team was identified as one of the most beneficial aspects of group exams, but after the exam only one student identified it as an advantage. At the same time, the number of responses identifying the opportunity to share and discuss ideas as a benefit has increased after having completed the exam. This is demonstrated in statements like:

"The group exam was useful, I did as much I could in the individual part, but in the group, mix my knowledge with others and listen to what they think of the question and what they did in the exam"

This seeming incongruity may be explained by differences in how students define teamwork, or simply by the students providing a more detailed response regarding the benefits of the practice (namely the opportunity to discuss) as a subset of a more general teamwork concept. The number of "Miscellaneous" (i.e. not fitting in other defined categories) challenges identified in responses increased significantly in the post-midterm survey, including an identification of some frustrations about weaker students receiving unwarranted grade increases due 
to the collaborative nature of the group exam. At the same time "being able to copy answers" appeared as an advantage of the practice. This may point to the particularly competitive environment found within the VC APSC program, as it relates to $2^{\text {nd }}$ year placement opportunities. All of these trends were further investigated during the focus group and interviews.

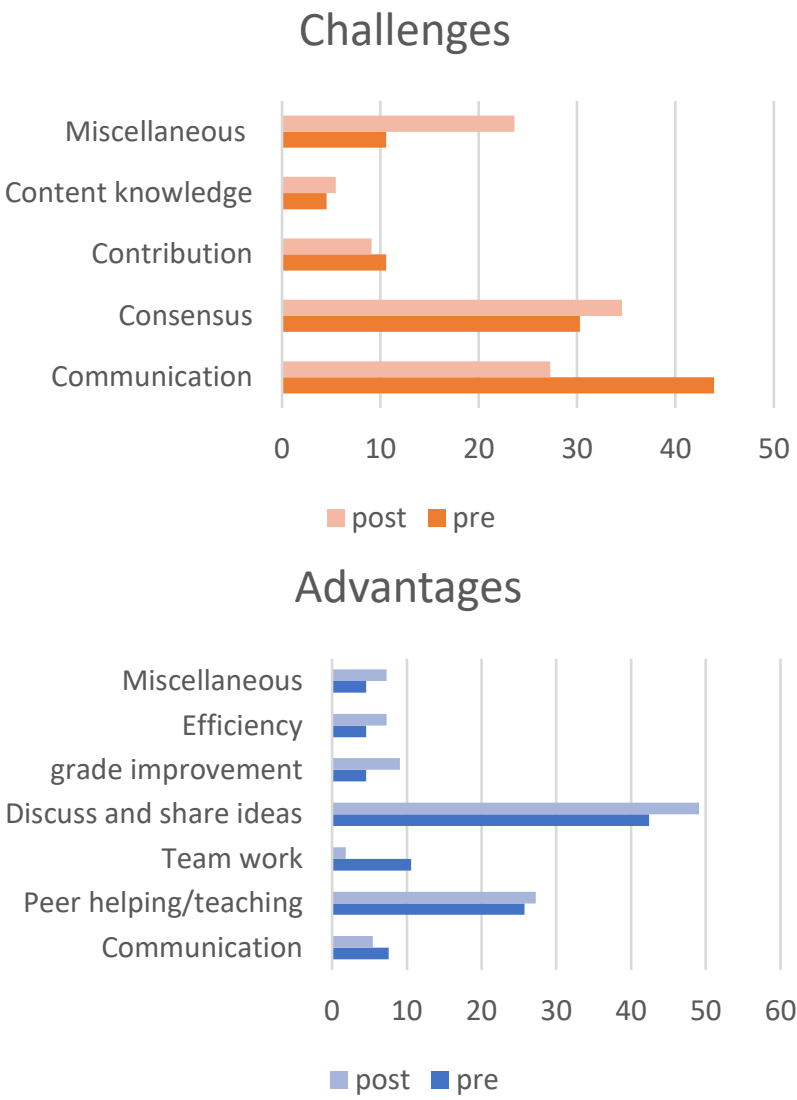

Fig 2. Changes in the students' perspective of challenges associated with (top) and advantages of (bottom) the twostage exam process, before and after having written one. $\mathrm{X}$-axis represents the percentage of responses commenting on the particular aspects listed on the $y$-axis.

\subsection{Focus Groups and Interviews}

Three students participated in the focus group, while as 7 students preferred one-on-one interviews. These students represented a good cross section of academic performance (62-88\% on the individual portion of the midterm) and of the student distribution (5 different countries of origin).

Participants were asked to elaborate on their positive and negative experiences during the group exam in interviews and/or a focus group to either add information about their responses, or help shed some light on the trends previously discussed. Three students accepted to participate in the focus group, and seven students opted to discuss the experience in one-on-one interviews.

Although students reported both positive and negative aspects of group exams, overall students agreed it was a positive experience. In the open-ended survey questions, many comments focused on grade improvements. In the interviews and focus group, the large majority of the positive aspects raised, although reflecting the perceived benefits of grade increases, also placed significantly more emphasis on an improvement in their confidence with and understanding of the material, as well as their confidence in their performance should they write another similar exam. This is demonstrated in comments like:

"The group exam is mostly good, because it can improve the marks, you can know your mistakes after the personal part is finished and you can understand [their team mates] way of thinking"

"I would like to have more group exams; it improves my grade and I can understand my mistakes right away"

In terms of negative aspects, some students mentioned that tension between team members did arise when some students felt they were not at the same level as their peers, or were intimidated by the process, preventing them from actively participating and thus benefitting from the process.

"Strong group members helped me review the exam and understand and fix my mistakes"

"Some students [did not participate] very much because they get a little bit disappointed about their own marks"

Although the experience was generally positive, when asked whether students would like to have more of these two-stage exams in other courses, the responses were quite mixed. On the one hand the students recognized the advantages described above, but there was some reluctance by stronger students to give "free points" to weaker students, and the particularly competitive environment found in VC APSC was specifically brought up multiple times. By means of context, all APSC students at UBC, whether direct-entry or VC students, take a common firstyear, at the end of which they rank their preferences for their $2^{\text {nd }}$-year disciplinary specialization. The placement process for $2^{\text {nd }}$ year is competitive, with some of the more popular programs therefore requiring a higher first-year average. In VC, further pressure is placed on the students in that an additional placement criteria is imposed as part of the logistics of the program, with half the students being placed at the Vancouver campus, and the other half at UBC's Okanagan campus, regardless of whether or not students meet the admission requirements of a particular program. Since, due to a variety of factors, the former option is by far preferred by students, and that placement 
is heavily based on first-year average, the practical result is that the top half of the class gets placed in Vancouver, and the bottom half gets placed at the Okanagan campus, whether or not students in the latter category meet the admission requirements for placement in a given discipline in Vancouver or if their program of choice is only available on that campus. This creates significant competition among students to be in the top half of the class, which explains a certain reluctance expressed by students to help their classmates. In fact, twice during interviews, when asked whether the students would like to have group exams in the future, the competition and its effect on collaboration was explicitly stated in comments like:

"If I am more weak in that course, yes I would like group exams because it will improve my grade. If I am more strong in that course, I still prefer individual exams so that my grades remain higher. [...] it is maybe not good, but we don't have a choice."

Anecdotally, this tension and competitiveness does not seem to be as prevalent in other VC APSC courses with heavy project and teamwork based core components, perhaps because collaboration is an integrated aspect of those courses.

Students whose group exam marks were significantly higher or lower than their individual mark were asked to provide explanations for this change. Of the two students that participated that received grade increases, both mentioned that the discussion allowed them to understand the mistakes they made on the individual portion, and that they felt they better understood the material and questions asked. They were also quite pleased for the grade increase. Of the two students whose marks decreased during the group portion of the exam, one explained that they were overruled by their team mates for the answer to a particular question, and that they were not able to convince them of the correct answer. The other students explained that they felt that they did very well on the individual portion of the exam, and that since they were guaranteed that mark in the case of a mark decrease, a concession made to students before the exam to allay some of their concerns about the process, once receiving significant pushback from team members during a disagreement on the correct solution to a problem, decided to simply disengage from the process.

Students were also asked why they thought that the importance of challenges related to communication skills decreased in survey responses after students had written the exam, and most confirmed the hypothesis that communicating with their classmates on technical material was not as challenging as they expected. It should be noted that in several groups, students reverted to their native languages when possible to facilitate the exchange of ideas. Although this worked very well for some groups all sharing a common language, this did result in isolation of some students not sharing a similar background.
During the interviews, students reported some difficulties reaching agreement among all team members, frustration at unequal participation or proficiency levels of some group members, all of which may help explain the drop in the number of survey responses indicating peer collaboration as an advantage. This is demonstrated in comments like:

"There were some fights in our group to explain some concepts to others, but it was fine because it deepen our understanding of these kind of problems"

\section{"A little bit of fighting in our group, but a lot in the group} next to us, where everyone had different answers"

Interestingly, although getting immediate feedback about understanding immediately after having written the individual component of an exam is one of the well documented advantages of this practice [6], students viewed this as both advantage and disadvantage. Some considered the immediate feedback as helpful to better understand the material they struggled with, others however reported that being wrong was an embarrassing moment in front of their peers, leading them to disengage from the group and not benefit from the process.

\subsection{Understanding and Retention of Material}

In order to try to assess whether working on the group exam helped with understanding and retention of the material, a topic that was explicitly assessed on the midterm, and another that was eligible as midterm content but not tested at that time, were tested on the final exam. Regarding the topic evaluated on the midterm, the average score for the relevant question on the individual portion (before the group portion) of the midterm was $65 \%$ while the average score on the final exam question covering the same topic, with the same level of difficulty, as evaluated by the instructor, was $76 \%(p<0.05)$, suggesting some advantage in terms of understanding and long-term retention of the group exam. Because this improvement in performance could have been due to more intensive preparation for the final exam as opposed to the midterm, the topic that could have been tested on the midterm (and thus would in theory have received as much study time while preparing for it) but was not included, was tested on the final with the average performance on the relevant question being $66.9 \%$, which is just slightly higher than the overall midterm average of $65.3 \%(p>0.05)$. Since the questions were all of similar complexity, and that equivalent practice material was provided to students, these results, though not strictly conclusive, suggest that the grade difference is not due entirely to better preparation for the final exam. It should be noted that due to the selfcontained modular nature of the course, material covered after the midterm would not have a significant impact on 
students' ability to answer questions from before the midterm. Although results suggest that it is possible that there is some value in the practice of group midterms in terms of students' comfort and longer term retention of the material, which would align with some previously published results, further work will be performed to separate any potential effect of group exams from other factors that could explain these results, which currently prevent the drawing of definite conclusions on this subject.

\section{INSTRUCTOR REFLECTION}

All data collected suggests that overall the experience was positive for students, and that most of the respondents saw some value in the practice of group midterms. Caution should be exercised in drawing strong conclusions in the data however given that the percentage of eligible responses (i.e. having correctly answered question 5 on the survey, demonstrating the respondents were reading the questions carefully) was relatively low, and thus possibly skewed towards stronger, more conscientious students. Of particular concern are the comments about the competitive environment in which instruction takes place. Although some competition is inevitable in most classroom settings and can even be leveraged to improve some learning outcomes, a stated reluctance to collaborate with or help other students is somewhat concerning and suggests an environment not conducive to learning and a significant source of stress, both of which would likely diminish the potential benefits of collaborative exams. Given that more data would be required before drawing conclusions, a more systematic study the competitiveness of the Vantage APSC environment, both hinted at by the results of this survey and attested to more anecdotally by Vantage instructors, should be conducted in the future, which would, among other things, provide a more solid grounding on which to base a decision on whether to continue implementing this type of group exam in VC APSC courses.

\section{CONCLUSIONS}

The results of this study align well with published data. Students report an overall positive experience with the practice, they self-reported a perceived increased understanding of the material and with their confidence in their technical abilities, and performance on midterm and final exam questions suggest that there may be some actual benefit in the collaborative exam practice in terms of longterm retention and understanding, although more data is required before drawing stronger conclusions on this point. Although the implementation of this assessment strategy seems to have had a positive impact on the students, the particular context in VC APSC presents some challenges related to technical communication, inclusivity, and high level of competition, which make it difficult to ensure that the benefits of the practice are shared by all participants. These will be investigated in future work, and addressed in future iterations of the course.

\section{Acknowledgements}

We gratefully acknowledge the financial support for this project provided by UBC Centre for the Integration of Research, Teaching, and Learning (CIRTL) via a Teaching as Research Award supporting Ms. Vaez Ghaemi's work. We also acknowledge valuable contributions from Nicolás Romualdi, and Brett Gilley.

\section{References}

[1] B. H. Gilley and B. Clarkston, "Collaborative Testing: Evidence of Learning in a Controlled In-Class Study of Undergraduate Students.," J. Coll. Sci. Teach., vol. 43, no. 3, pp. 83-91, 2014.

[2] K. Garaschuk and E. Cytrynbaum, "Feasibility and effectiveness of group exams in mathematics courses," vol. 1970,2018

[3] H. Jang, N. Lasry, K. Miller, and E. Mazur, "Collaborative exams: Cheating? Or learning? Collaborative exams: Cheating ? Or learning ?," vol. 223, 2017.

[4] R.V. Ghaemi and G. Potvin, "Implementation of a Two-Stage Exam in First-Year Physical Chemistry Courses For International Engineering Students", Proc. Can. Eng. Ed. Assoc., 3, 2018.

[5] C. E. Wieman, G. W. Rieger, and C. E. Heiner, "Physics Exams that Promote Collaborative Learning," vol. 51, no. 2014, 2017.

[6] Y. Cao and L. Porter, "Impact of Performance Level and Group Composition on Student Learning during Collaborative Exams," pp. 152-157, 2017.

[7] B. Bruno et al., "Two-Stage Exams: A Powerful Tool for Reducing the Achievement Gap in Undergraduate Oceanography and Geology Classes," Oceanography, vol. 30, no. 2, 2017. 